\title{
CORRIGENDUM
}

\section{Effect of Zinc Deficiency on the Biosynthesis of Phosphatidylcholine in Rat Microsomes}

\author{
W. E. Cornatzer, ${ }^{*}$ Judy A. HANing, James C. Wallwork, \\ AND HAROLD H. SANDSTEAD
}

Guy and Bertha Ireland Research Laboratory, Department of Biochemistry and Molecular Biology, University of North Dakota, School of Medicine, and Grand Forks Human Nutrition Research Center, Agricultural Research Service, US Department of Agriculture, Grand Forks, ND 58202

The table on the following two pages is a corrected version of the one that appeared in Biological Trace Element Research, vol. 6, October, 1984 on pp. 398 and 399. 


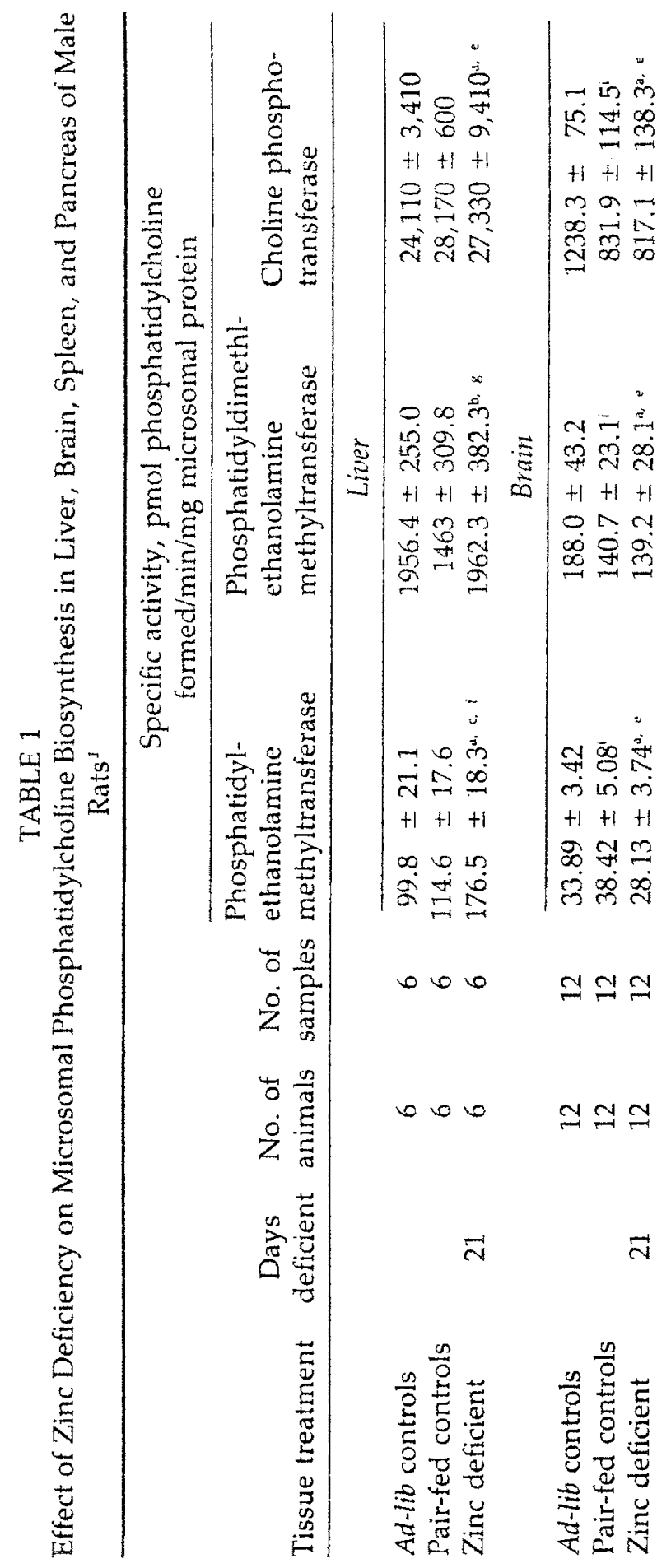




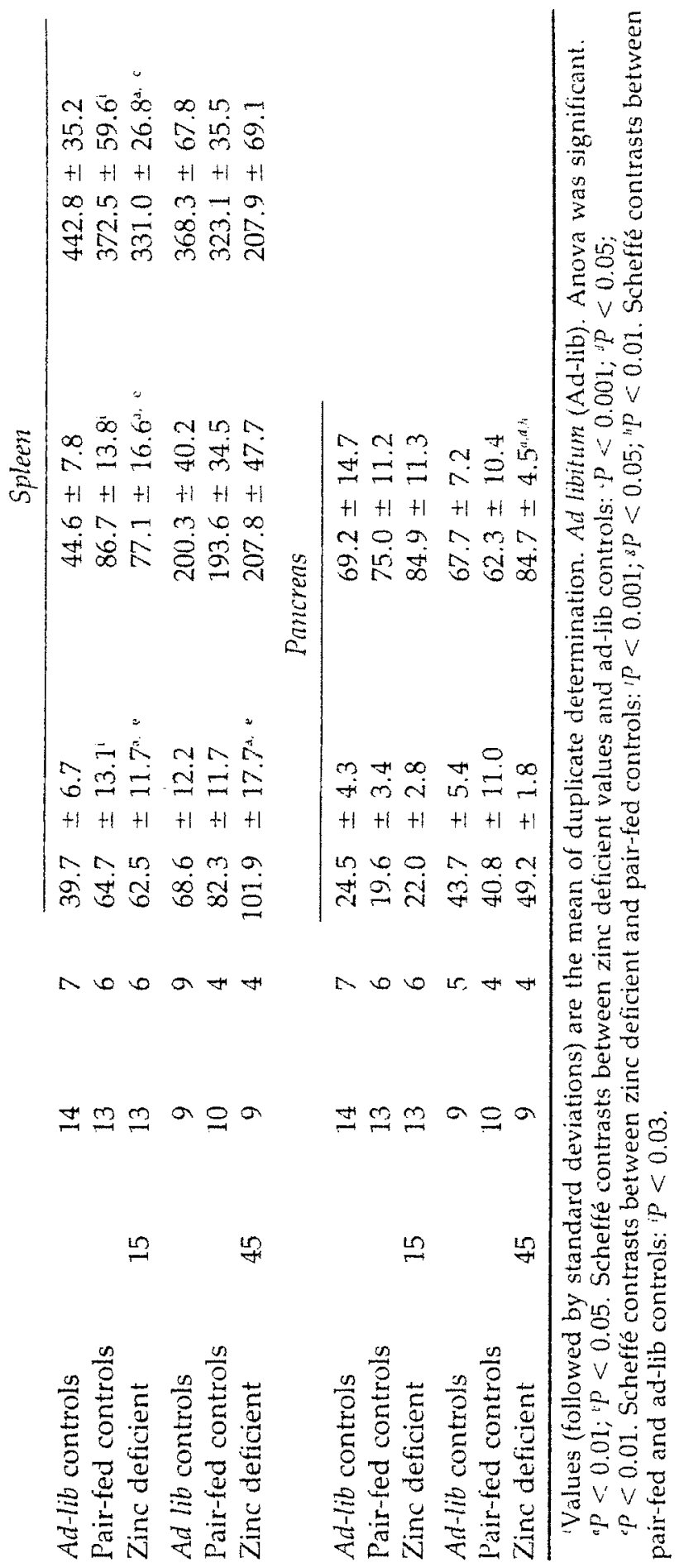

